\title{
Using General System Approach For Product Lifecycle Management Software Selection And Evaluation
}

\author{
Keh-Wen "Carin” Chuang, Purdue University North Central, USA \\ Kuan C. Chen, Purdue University Calumet, USA
}

\begin{abstract}
Product Lifecycle Management (PLM) is the process of managing the entire lifecycle of a product from its conception, through design and manufacture, to service and disposal. One of the toughest aspects of PLM implementations is choosing the appropriate software. In order to choose the right software that meets the business requirements, it is necessary to have a systematic view to serve as an evaluation guideline for advice from an independent third-party and that can guide decision makers through a structured process and understands the entire PLM market. This is an important aspect of the PLM assessment and planning process. This study built a systems model to fulfill the PLM software selection and evaluation needs.
\end{abstract}

Keywords: Product lifecycle management, general system approach, software selection and evaluation.

\section{INTRODUCTION}

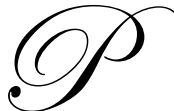

roduct Lifecycle Management (PLM) is the activity of managing a company's products all the way across their lifecycles in the most effective way. PLM helps a company get control of its products and services and enables it to take responsibility for them across their lifecycles. Mastering the activities in the lifecycle makes it easier to provide reliable products, sell services on them, and even sell services on competitors' products (Stark, 2006). However, one lesson learned from experience is that PLM enterprise applications should not be selected in a vacuum (Jakovljevic \& Brown, 2003). The needs and requirements of multiple departments, and even business partners, must be represented in the documented requirements, as well as on the selection team. PLM evaluations should involve the IT organization, finance, engineering, marketing, and operations (Malykhina, 2004.) It is important that the system handle a broad view of the product in order to promote cross-departmental use, visibility, and collaboration. Systems that focus on any one department may alienate potential users (Rudd, 2004).

PLM serves as the vital backbone information system of the enterprise, helping a company achieve the efficiency, agility, and responsiveness required to succeed in a dynamic business environment. However, properly implementing PLM is a difficult and costly process that has caused serious business losses for some companies that underestimated the planning, development, and training necessary to re-engineer their business processes to accommodate their new PLM systems (Olson, 2004).

In this paper, we use the general system approach to explore the nature of the PLM software selection and evaluation model and suggest ways that it can be used explicitly in industry to help the customers align their users' needs on standard product functionality. These key components will serve as foundation information to build a conceptual system model that explores the implementation system behavior. The system model will guide the PLM decision makers and administrators as they attempt to steer the implementation clear of these obstacles. The relationships in the model are designed to be simple and functional and do not necessarily represent any particular business environments. It is meant to be a generic PLM selection and evaluation system model with implications for scenario planning sequences. It allows PLM-related administrators to move away from the discrepancy between the 
real world symptoms and simple software installation. The interrelationships of five primary sectors of the PLM implementation system are presented in this paper. They include: [1] company characteristics, [2] PLM implementation plan, [3] communication, [4] user, and [5] technology management. There are interactions within each of these sectors depicted by system loop map.

\section{A PLM SELECTION AND EVALUATION SYSTEM MODEL}

The literature provides some guidelines for a generic course development model of a PLM selection and evaluation system model. The critical areas that a company should examine on the PLM software candidates are as follows (Jakovljevic \& Brown, 2003):

- $\quad$ General administration

- $\quad$ Product architecture and integration (i.e., support for various OS platforms and databases)

- The ability to integrate with various enterprise applications (e.g., ERP, SCM, CAD, content management, e-commerce, common office automation products, groupware, and e-mail)

- $\quad$ Support for various standards and the manner in which the system provides access to metadata and file system data

- $\quad$ Document management and vaulting (i.e., support for storing documents of any type within the system with the ability to maintain revision control and audit trails, check-in and check-out capability, versioning, indexing, etc.)

- Information structures (the ability to store and manage complex information structures, support versioning, edit in a graphical or text-based mode, make comparisons between two information structures, and provide different views of the information structure)

- Workflow and event management

- $\quad$ Sourcing

- $\quad$ Product transition

- $\quad$ Product development (the creation of product portfolios and folders, the ability to save conceptualizations, the definition of a development schedule, the automation of the ECO process, and the ability to collaborate with various user groups)

- $\quad$ Change management

- $\quad$ Requirements management

- $\quad$ Visualization (integration with 2-D and 3-D design tools)

- $\quad$ Project management (e.g., Gantt-based planning, management, and support for a work breakdown structure)

Based on our review of the literature and our examination of current PLM implementation problems, we propose a PLM implementation system model consisting of five sectors: [1] company characteristics, [2] PLM implementation plan, [3] communication, [4] user, and [5] technology management. How these areas function together and interact with each other is shown in Figure 1.

\section{COMPANY CHARACTERISTICS}

Three factors are behind the PLM implementation progress: industry characteristics, organizational structure, and company size. In this sector, we look at interrelationships between these three factors. For example, the company size will have impact from the cost/budget system to the PLM investment decision. Also, organizational structure will be related to resource administration and affect the PLM control. In general, more sophisticated organization structure will have more resistance from each segment because the resources and information sharing always involve human factors and politics. Industry characteristics are the keys to success for PLM implementation. IT-related industries have more intention to organize resources in PLM and more sensitive data-related industries (e.g. accounting) would have less interest in using PLM. 


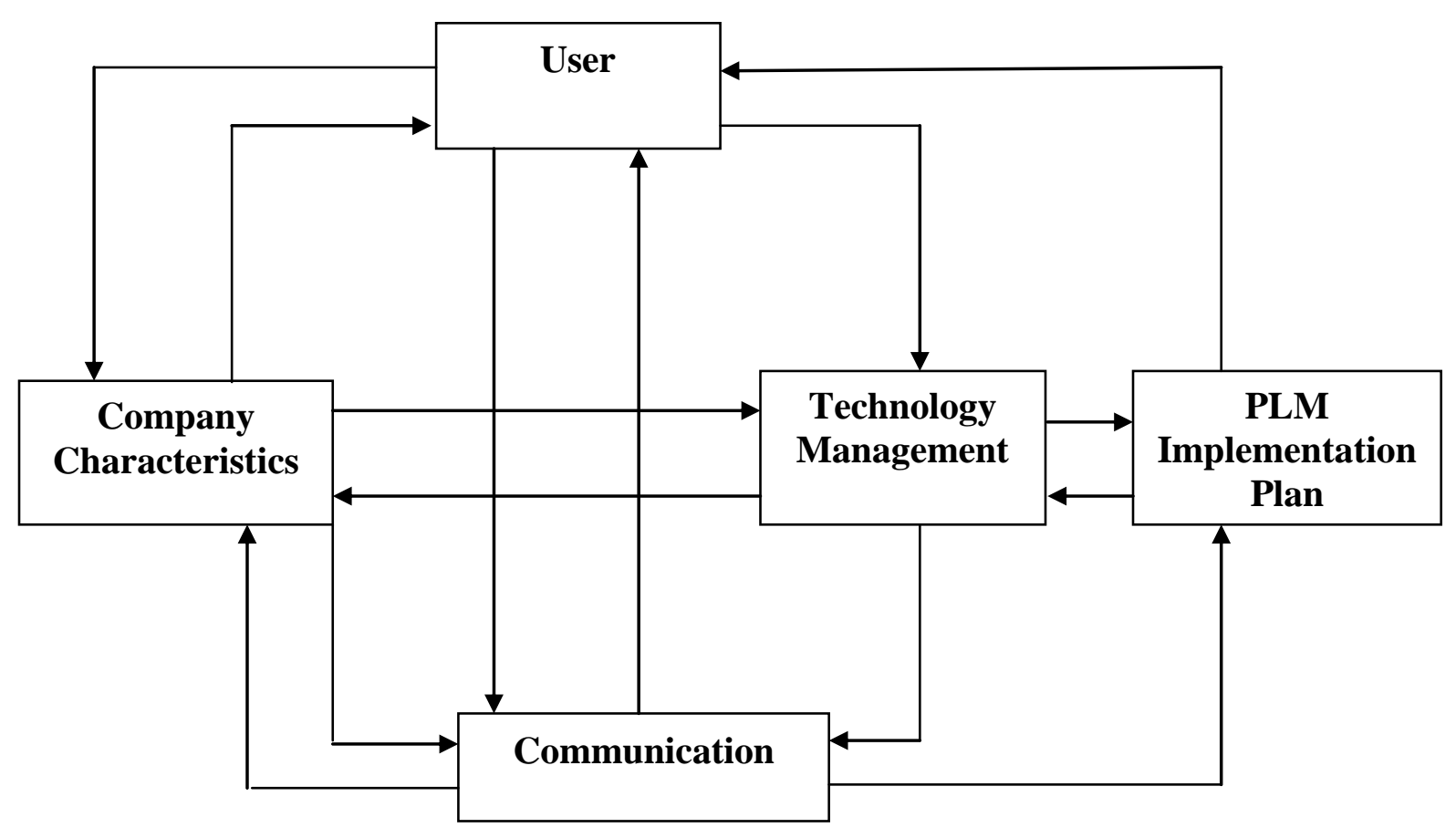

Figure 1: A PLM Software Selection and Evaluation System Model

\section{COMMUNICATION}

Communication is a key implementation consideration because there are so many user groups impacted by a PLM program both internal (e.g., Stakeholders, System Operators) and external to the Company (e.g., investors). A communication strategy that includes tactical methods of disseminating PLM program information both top-down and bottom-up via diverse communication channels is an effective approach that contributes to implementation plan success (Enterprise Solution Competency Center Report, 2006).

\section{PLM IMPLEMENTATION PLAN}

Business managers and IT professionals have been the major cause of PLM failures. The reason given is that these individuals underestimate the complexity of the planning, development, and training that are needed to prepare for a new PLM system that would radically change their business processes and information systems. Failure to involve affected employees in the planning and development phases and change management programs, or trying to do too much too fast in the conversion process, are also typical causes of failed PLM projects. Insufficient training in the new work tasks required by the PLM system, and failure to do enough data conversion and testing, are other causes of failure. In other cases, PLM failures are also due to over reliance by company or IT management on the claims of PLM software vendors or the assistance of prestigious consulting firms hired to lead the implementation. Identify the factors that led to the development of Product lifecycle management (PLM) systems. It will assist the distinguishing characteristics of PLM software. Also, exploring the pros and cons of implementing a PLM system will enhance ongoing developments in PLM (Roa, 2000).

\section{USER}

In non-PLM development projects, the conventional wisdom is to include users on the project team. In a PLM implementation, the parallel is to include users from across the affected functional areas. This insures that 
consensus is reached on requirements an also helps buy-in to occur. If the people in the different departments that will use PLM don't agree that the work methods embedded in the software are better than the ones they currently use, they will resist using the software or will want IT to change the software to match the ways they currently do things. This is where PLM projects break down (Koch, 2006).

PLM users are the company's employees. A company's employees are the most valuable asset to the company. Companies realize that a well-trained and experienced employee is very valuable and have begun to use the term "human capital management." Good management of employees is even more important in a large organization. Effective information systems can help manage employees (Jiang, 2005).

\section{TECHNOLOGY MANAGEMENT}

In technology, PLM implementation will involve software selection, data conversation, integration, testing, software customization and data analysis. Based on Deloitte Consulting survey of 64 Fortune 500 companies, one in four admitted that they suffered a drop in performance when their PLM system went live. Performance becomes the difficulty in PLM implementation. It is very costly to have customization efforts to modify the PLM software to fit with powerful users' needs. Customizations make the software more unstable and harder to maintain when it finally does come to life. There are five types of PLM tools: Dassault Systems PLM Suite of Tools, Unigraphics PLM Suite of Tools, PTC Suite of Tools, and Autodesk Suite of Tools. Because PLM covers so much of what a business does, a failure in the software can bring a company to a halt, literally. It is important to have technology management of how PLM controls the flow of information for the each department (Summer, 2000).

\section{CONCLUSION}

Product lifecycle management is an integrated, information-driven approach to all aspects of a product's life, from its design through manufacture, deployment, and maintenance - culminating in the product's removal form service and final disposal. PLM software suites enable accessing, updating, manipulating, and reasoning of product information that is being produced in a fragmented and distributed environment.

PLM evaluations should involve the IT organization, finance, engineering, marketing, and operations (Malykhina, 2004). Most companies should create a joint committee or task force to evaluate how the software candidate can improve enterprise-wide product lifecycle management. Although PLM often starts with strong engineering management, it will eventually extend beyond it to almost all areas of corporate activity. Thus, companies choosing PLM suites should consider both their current PLM tools and future integration with key business-area solutions (e.g., ERP, CRM, and SCM).

It is important that the system handle a broad view of the product in order to promote cross-departmental use, visibility, and collaboration. Systems that focus on any one department may alienate potential users (Rudd, 2004). Besides, PLM is, by nature, a collaborative solution. Look for the software that supports current web-based technologies to speed both internal and external collaboration efforts. The manufacturers should first make sure that the PLM functionality they require is available from the solutions they are evaluating. When evaluating the applicability of PLM software, it is crucial to define the business needs in advance. Depending on the needs to be addressed, industry may play a critical role. Look for the vendors with significant industry history and avoid vendors whose solution is intended to serve too many industries outside of yours.

In summary, be careful to remain flexible and not automatically settle for incumbent software if the products and plans do not match up well to the company's strategic requirements. In addition, the PLM activities should be focused on immediate results, company should not fall in the trap of "low-hanging fruit" and easily obtainable short-term return on investment benefits (ROI) at the expense of long-term strategic benefits that are either of a "soft" nature or are of lower value in the short-term (Jakovljevic \& Brown, 2003). 


\section{AUTHOR INFORMATION}

Keh-Wen (Carin) Chuang, MS. is an assistant professor in the Department of Computer \& Information Technology at Purdue University North Central. Before entering academia, Professor Chuang has been spent over 12 years of professional experience in database administration and information system development for three Fortune 100 companies in Illinois, Indiana and Michigan. Professor Chuang is a certified JAVA developer, SQL Server Administrator and E-Commerce Web Site Developer.

Professor Chuang earned her two Master degrees in Information Systems and Urban Studies at Michigan State University, and her BBA in International Economics from Soochow University at Taiwan.

Kuan C. Chen, Ph.D. is Head of Department Information Systems in the School of Management at Purdue University Calumet in Hammond, Indiana. Dr. Chen has extensive experience in MIS research topics. He has authored numerous journal papers on topics varying from project management to Information Technology (IT) economics. He has also been a contributing author on several books and a technical editor on numerous books and journal articles. Dr. Chen maintains an active Web development and database consulting practice in both the U.S. and Taiwan. He has a Ph.D. in MIS and another Ph.D. in Economics, both from Michigan State University.

\section{REFERENCES}

1. Enterprise Solution Competency Center (2006). http://www.army.mil/aeioo/erp/keyic.htm

2. Jakovljevic, P. \& Brown, J. (2003). Selecting a PLM Vendor. http://www.technology-evaluation.com/

3. Jiang, Y. (2005). Critical success factors in PLM implementation in Finland. The Swedish School of Economics and Business Administration. Unpublished Mater Thesis.

4. Koch, C. (2003). The ABCs of ERP. from http://www.cio.com/research/erp/edit/erpbasics.html

5. Malykhina, E. (2004) PLM Software Is Put To Work. InformationWeek. http://www.informationweek.com/

6. Monk, E., \& Wagner, B. (2006). Concepts in Enterprise Resource Planning. Boston: Course Technology.

7. O'Brien, J. A. (2006). Management Information Systems. New York: Irwin/McGraw Hill.

8. Olson, M. (2004). Managerial issues of Enterprise Resource Planning Systems. New York: McGraw-Hill.

9. Ptak, C., \& E., S. (2000). ERP: tools, techniques, and applications for integrating the supply chain. Boca Raton: Lucie Press.

10. Roa, S. (2000). Enterprise resource planning: Business needs and technologies. Industrial Management \& Data Systems, 100(2), 81-88.

11. Rudd, R. (2004) Should Your Software Selection Process Have a Proof of Concept? Technology Evaluation Centers. http://www.technology-evaluation.com/

12. Stark, J. (2006). Product Lifecycle Management: $21^{\text {st }}$ Century paradigm for Product Realisation. London: Springer. 2-15.

13. Summer, M. (2000). Risk factors in enterprise-wide/PLM projects. Journal of Information Technology, 15(4), 317-328.

14. Turban, E., Leidner, D., \& McLean, E. R. (2006). Information Technology for Management. Edison: John Wiley \& Sons.

15. Umble, J. E., Haft, R. R., \& Umble, M. M. (2003). Enterprise resource planning: Implementation procedures and critical success factors. European Journal of Operational Research, 146, 241-257.

16. Vervill, J., \& Haingten, A. (2003). A six-stage model of the buying process for PLM software. Industrial Marketing Management, 5560, 1-10. 
NOTES 